\title{
Measuring kiwifruit resistance to armoured scale insect pests
}

\author{
M.G. Hill, N.A. Mauchline and K.A. Stannard \\ Garry Hill, Plant E Food Research, 412 No1 Rd, RD2, Te Puke 3182, New Zealand \\ Corresponding author: Garry.Hill@plantandfood.co.nz
}

\begin{abstract}
A bioassay for assessing relative susceptibility of kiwifruit germplasm to latania scale (Hemiberlesia lataniae) has been developed and validated. The method uses cut canes collected from dormant kiwifruit vines in winter. Canes are held in coolstore $\left(0^{\circ} \mathrm{C}\right)$ until required. Lengths of cane $(40 \mathrm{~cm})$ are held with one end in water at $20^{\circ} \mathrm{C}$ and scale insect crawlers from laboratory cultures are encouraged to settle beneath wool wrapped around the cane. Percentage crawler settlement, numbers of insects surviving to adulthood and their size are determined and used to assess the relative susceptibility of the plant. This method has been validated for $H$. lataniae and used to study kiwifruit resistance and defensive responses. The bioassay did not work satisfactorily for greedy scale (H. rapax) as crawler settlement was very low. Further research has identified cane age as an important determinant of $H$. rapax crawler settlement. Young canes harvested in summer enable good settlement of $H$. rapax but canes of this age do not last long enough for the insects to mature (10-12 weeks). Canes harvested in autumn while still green will survive to support $H$. rapax settlement, growth and survival, and can be used to compare kiwifruit resistance to both scale species.
\end{abstract}

\section{Rearing of chelifers for potential biocontrol of varroa mites}

\author{
S. Read, B.G. Howlett, B.J. Donovan, W.R. Nelson, R.F. van Toor and G. Leung \\ Plant E Food Research, Lincoln 8120, New Zealand \\ Corresponding author: sam.read@plantandfood.co.nz
}

Honeybee colonies infested with the varroa mite (Varroa destructor) usually collapse unless they have been treated with acaracides. Resistance to the most commonly used acaracides is increasing and no biological control options are yet available. Chelifers (pseudoscorpions) are generalist predators and may have potential as a biological control agent. This poster describes an attempt to establish breeding populations of native chelifers, which have been shown to actively feed on varroa, with the ultimate aim of testing their ability as a biological control of varroa. Two species of chelifers (Nesochernes gracilis and Heterochernes novaezealandiae) collected from honeybee hives and in leaf litter near apiaries at Katikati (Bay of Plenty) are being maintained in the laboratory. They are surviving on a variety of different food sources such as Drosophila sp. larvae (fruit fly), aphids (Acyrthosiphon pisum) and moth larvae (Helicoverpa armigera, Spodoptera litura and Plodia interpunctella). With little known about raising these chelifers in captivity, their diet preferences and feeding periods are being obtained as a first step to obtaining the basic information necessary for potential commercial propagation of chelifers for varroa control in honeybee hives. 